\title{
Decreased pulmonary vascular distensibility in adolescents conceived by in vitro fertilization
}

\author{
K. Forton 1,2, Y. Motoji 1,2 , B. Pezzuto' ', S. Caravita ${ }^{2,3}$, A. Delbaere ${ }^{4}$, \\ R. Naeije ${ }^{1,5}$, and V. Faoro ${ }^{1, *}$
}

\begin{abstract}
'Cardiopulmonary Exercise Laboratory, Faculty of Motor Science, Université Libre de Bruxelles, I070 Brussels, Belgium, 2Department of Cardiology, Erasmus University Hospital, 1070 Brussels, Belgium, ${ }^{3}$ Department of Cardiovascular, Neural and Metabolic Sciences, Ospedale San Luca, Istituto Auxologico Italiano IRCCS, 20149 Milano, Italy, ${ }^{4}$ Fertility Clinic, Erasmus University Hospital, 1070 Brussels, Belgium and ${ }^{5}$ Laboratory of Physiopathology, Faculty of Medicine, Université Libre de Bruxelles, 1070 Brussels, Belgium

*Correspondence address. Cardio-Pulmonary Exercise Laboratory, Faculty of Motor Science, Université Libre de Bruxelles, Erasme Campus, 808 Lennik Road CP640, 1070 Brussels, Belgium. E-mail: vfaoro@ulb.ac.be
\end{abstract}

Submitted on February 10, 2019; resubmitted on April 23, 2019; editorial decision on May 28, 2019

\begin{abstract}
STUDY QUESTION: What is the functional relevance of decreased pulmonary vascular distensibility in adolescents conceived by IVF?
SUMMARY ANSWER: Children born by IVF have a slight decrease in pulmonary vascular distensibility observed during normoxic exercise that is not associated with altered right ventricular function and aerobic exercise capacity.
\end{abstract}

WHAT IS KNOWN ALREADY: General vascular dysfunction and increased hypoxic pulmonary hypertension have been reported in ART children as compared to controls. Pulmonary hypertension or decreased pulmonary vascular distensibility may affect right ventricular function and thereby possibly limit maximal cardiac output and aerobic exercise capacity.

STUDY DESIGN, SIZE, DURATION: This prospective case-control study enrolled 15 apparently healthy adolescents conceived by IVF/ICSI after fresh embryo transfer paired in a 2 to I ratio to 30 naturally conceived adolescents between March 2015 and May 2018.

PARTICIPANTS/MATERIALS, SETTING, METHODS: Fifteen IVF/ICSI adolescents and 30 controls from singleton gestations matched by age, gender, weight, height and physical activity underwent exercise echocardiography, lung diffusion capacity measurements and a cycloergometer cardiopulmonary exercise test. A pulmonary vascular distensibility coefficient $\alpha$ was determined from the pulmonary arterial pressure (PAP) versus cardiac output $(\mathrm{Q})$ relationships. Pulmonary capillary volume $(\mathrm{Vc})$ was calculated from single breath nitric oxide and carbon monoxide lung diffusion capacity measurements $\left(\mathrm{DL}_{\mathrm{CO}}\right.$ and $\left.\mathrm{DL} \mathrm{L}_{\mathrm{NO}}\right)$ at rest and during exercise $(100 \mathrm{~W})$. Eight of the IVF subjects and eight controls underwent a 30 min hypoxic challenge at rest with a fraction of inspired oxygen of 0.12 to assess hypoxic pulmonary vasoconstriction.

MAIN RESULTS AND THE ROLE OF CHANCE: In normoxia, oxygen uptake $\left(\mathrm{VO}_{2}\right)$, blood pressure, $D L_{C O}$, $D L_{N O}$, echocardiographic indices of right ventricular function, $Q$ and PAP at rest and during exercise were similar in both groups. However, IVF children had a lower pulmonary vascular distensibility coefficient $\alpha(1.2 \pm 0.3$ versus $1.5 \pm 0.3 \% / \mathrm{mmHg}, P=0.02)$ and a blunted exercise-induced increase in Vc ( 24 versus $32 \%, P<0.05$ ). Hypoxic-induced increase in pulmonary vascular resistance in eight IVF subjects versus eight controls was similar.

LIMITATIONS, REASONS FOR CAUTION: The IVF cohort was small, and thus type I or II errors could have occurred in spite of careful matching of each case with two controls. ART evolved over the years, so that it is not certain that the presently reported subtle changes will be reproducible in the future. As the study was limited to singletons born after fresh embryo transfers, our observations cannot be extrapolated to singletons born after frozen embryo transfer.

WIDER IMPLICATIONS OF THE FINDINGS: The present study suggests that adolescents conceived by IVF have preserved right ventricular function and aerobic exercise capacity despite a slight alteration in pulmonary vascular distensibility as assessed by two entirely different methods, i.e. exercise echocardiography and lung diffusing capacity measurements. However, the long-term prognostic relevance of this slight decrease in pulmonary vascular distensibility needs to be evaluated in prospective large scale and long-term outcome studies.

(c) The Author(s) 2019. Published by Oxford University Press on behalf of the European Society of Human Reproduction and Embryology. All rights reserved.

For permissions, please e-mail: journals.permission@oup.com. 
STUDY FUNDING/COMPETING INTEREST(S): Dr Caravita was supported by an ERS PAH short term research training fellowship (STRTF20 I4-5264). Dr Pezzuto was funded by an Italian Society of cardiology grant. Dr Motoji was supported by a grant from the Cardiac Surgery Funds, Belgium. All authors have no conflicts of interests to declare.

Key words: long-term outcome of ART children / pulmonary vascular resistance / $\mathrm{VO}_{2}$ max / hypoxia / lung diffusion capacity / echocardiography

\section{Introduction}

In developed countries, 1-6\% of children are currently conceived by ART, mostly IVF and ICSI (Calhaz-Jorge et al., 20 I5; Goisis et al., 20 I9; Pinborg et al., 2019). Even though these procedures are generally considered to be safe, there are remaining concerns about their longterm health consequences (Celermajer, 20 I 2; Calhaz-Jorge et al., 20 I5, Goisis et al., 2019; Pinborg et al., 2019). As recently reviewed, several studies have suggested that individuals conceived by ART might be at risk of developing increased adiposity, glucose intolerance and hypertension, although there is no general agreement on these findings and correction for confounding factors such as maternal hormonal environment following ovarian stimulation, embryo culture conditions, fresh or frozen embryo transfer, single or multiple embryo replacement and parental age and/or infertility (Pinborg et al., 2019).

In 2012, Scherrer et al. (2012) reported on increased arterial stiffness, altered flow-induced systemic vascular responses and enhanced altitude-induced increase in pulmonary arterial pressure (PAP) at Doppler echocardiography in ART children as compared to controls, suggesting generalized vascular dysfunction and increased pulmonary vascular reactivity to hypoxia. The authors excluded parental factors as vascular function was normal in children conceived after induction of ovulation and in siblings of ART children who were conceived naturally (Scherrer et al., 20I2). These results were confirmed in ART mice (Rexhaj et al. 2013) and supported by subsequent echocardiographic observation of increased right ventricular (RV) dimensions with diastolic dysfunction and increased tricuspid regurgitation (TR) in IVF children brought to the altitude of $3454 \mathrm{~m}$ (Von Arx et al. 20I5).

Until now, pulmonary vascular dysfunction in IVF children have only been reported under hypoxic stress. The purpose of the present study is to evaluate if this abnormality is confirmed in normoxic condition under an exercise stress and evaluate the impact on right ventricular function and aerobic exercise capacity (maximum oxygen uptake, $\mathrm{VO}_{2}$ max). We therefore tested the hypothesis that exercise stress echocardiography of the right ventricle and pulmonary circulation combined with lung diffusing capacity $\left(D_{L}\right)$ measurements might uncover altered pulmonary vascular function in IVF adolescents in normoxic conditions and, if so, impact on right ventricular function and $\mathrm{VO}_{2} \mathrm{max}$.

Exercise stress echocardiography is increasingly used in the assessment of cardiovascular diseases and detection of early pathological changes in the pulmonary circulation (Rudski et al., 2018). We previously reported on the approach to show sex-, age- and race-related differences in pulmonary vascular distensibility (Argiento et al., 2012; Simaga et al., 2015). The methodology of the measurement of alveolocapillary membrane (Dm) and capillary blood volume (Vc) components of lung diffusing capacity using carbon monoxide (CO) and nitric oxide (NO) as tracer gases has been recently updated (Zavorsky et al., 2017). Both lung diffusing capacity and vascular distensibility have been reported to be positively correlated to $\mathrm{VO}_{2} \max$ (Lalande et al., 2012; Simaga et al., 2015; Simaga et al., 2017; Zavorsky et al. 2017), supporting the notion of 'pulmonary vascular reserve' as an important determinant of aerobic exercise capacity (La Gerche et al., 20l0). A higher pulmonary vascular reserve and thus a greater capacity of the pulmonary circulation to recruit and distend with increasing flow, in order to reduce pulmonary vascular resistance (PVR) and extend the capillary bed for gas exchanges, would decrease right ventricular afterload and consequently increase maximal cardiac output and $\mathrm{VO}_{2}$ max (La Gerche et al., 20 I0, Lalande et al. 20I2). Conversely, a hypothetical decrease in pulmonary vascular reserve in IVF children could possibly lead to a decreased right ventricular function and an aerobic exercise capacity limitation.

\section{Methods}

\section{Study population}

Fifteen apparently healthy IVF/ICSI offspring including I 3 adolescents and 2 young adults (Mean \pm SD; age: $15 \pm 3$ years old ranging from II to 24 years old; height: $167 \pm 12 \mathrm{~cm}$; weight: $57 \pm$ I I kg; BMl: $20.2 \pm 2.7 \mathrm{~kg} / \mathrm{m}^{2}$; body surface area (BSA): $1.64 \pm 0.22 \mathrm{~m}^{2}$; girl/boy ratio: $7 / 8$ ) were paired in a 2 to 1 ratio to 30 healthy controls matched by age, sex, weight, height and physical activity (Mean $\pm \mathrm{SD}$; age: $15 \pm 3$ years old; height: $167 \pm 1 \mathrm{l} \mathrm{cm}$; weight: $56 \pm 1 \mathrm{l} \mathrm{kg}$; BMl: $19.8 \pm 2.8 \mathrm{~kg} / \mathrm{m}^{2}$; BSA: $1.62 \pm 0.20 \mathrm{~m}^{2}$; girl/boy ratio: 14/16). The IVF adolescents/young adults were recruited by telephone calls to the parents known at the Fertility Clinic of the Erasmus University Hospital, Brussels. All subjects were normally active, with an estimated 3 to 4 hours active exercise time per week. None of them were smokers or took any drugs and were declared in perfect health by themselves and by their parents. Among the ART subjects, 4 were conceived by classical IVF and I I by ICSI. All of them were singletons and were conceived via the transfer of fresh embryos. None had been born prematurely with a gestational time ranging from 37 to 40 weeks. Control naturally conceived adolescents were recruited in the same communities, attended the same schools and practiced the same amount of physical exercise per week.

\section{Ethical approval}

The adolescents/young adults and both parents of minor subjects gave an informed consent to the study, which was approved by the local Institutional Ethical Committee (reference B40620|422389).

\section{Experimental protocol}

All the subjects underwent a clinical examination followed by a resting and exercise echocardiography in a semi-recumbent position coupled to lung diffusion capacity for $\mathrm{NO}$ and $\mathrm{CO}\left(\mathrm{DL}_{\mathrm{NO}}\right.$ and $\left.\mathrm{DL} \mathrm{CO}\right)$ mea- 
surements. During exercise stress echocardiography, measurements of blood pressure (BP), cardiac output (Q), PAP and left atrial pressure (LAP) were taken at rest and at increasing levels of exercise, by 20 Watts (W) every 2 min until exhaustion on an echocardiographic cycloergometer. $D L_{C O}$ and $D L_{N O}$ were measured at rest and at $100 \mathrm{~W}$.

A classical incremental cycle ergometer cardiopulmonary exercise test (CPET) was performed on another visit. Ventilation $\left(V_{E}\right)$, oxygen uptake $\left(\mathrm{VO}_{2}\right)$, carbon dioxide output $\left(\mathrm{VCO}_{2}\right)$ and transcutaneous pulse oximetry $\mathrm{O}_{2}$ saturation $\left(\mathrm{SpO}_{2}\right)$ were measured at rest and at increasing workloads until exhaustion.

Eight of the IVF subjects (Mean $\pm \mathrm{SD}$; age: $20 \pm 4$ years old; height: $175 \pm 8 \mathrm{~cm}$; weight: $63 \pm 7 \mathrm{~kg}$; BMI: $20.5 \pm \mathrm{I} .1 \mathrm{~kg} / \mathrm{m}^{2}$; BSA: $1.76 \pm 0.14 \mathrm{~m}^{2}$; girl/boy ratio $4 / 4$ ) and eight controls (Mean $\pm S D$; age: $19 \pm 4$ years old; height: $176 \pm 10 \mathrm{~cm}$; weight: $65 \pm 6 \mathrm{~kg}$; BMI: $20.9 \pm 1.2 \mathrm{~kg} / \mathrm{m}^{2}$; BSA: $1.80 \pm 0.14 \mathrm{~m}^{2}$; girl/boy ratio 4/4) underwent an echocardiographic examination at rest after 15 and 30 min of hypoxic challenge with a fraction of inspired $\mathrm{O}_{2}\left(\mathrm{FIO}_{2}\right)$ of 0.12 . This severity of hypoxia corresponds to an altitude of $4500 \mathrm{~m}$ and is known to be well tolerated with minimal changes in arterial $\mathrm{PCO}_{2}$ (Maggiorini et al., 200 I). The low $\mathrm{FIO}_{2}$ was administrated by using a tightly collarfitted helmet (Castar; Brussels, Belgium), and inspired and expired $\mathrm{O}_{2}$ and $\mathrm{CO}_{2}$ were monitored with analyzers (Datex; Aartselaar, Belgium).

\section{Clinical assessment}

The clinical assessment included a medical and birth history and a clinical examination including measurements of resting BP (sphygmomanometry), $\mathrm{SpO}_{2}$ (Nellcor Puritan Bennett Inc, Pleasanton, $\mathrm{CA}$ ) and electrocardiogram.

\section{Echocardiography}

Standard M-mode, two-dimensional and Doppler images were acquired with a commercially available portable system (CX50 CompactXtreme Ultrasound System; Philips, Amsterdam, The Netherlands) in agreement with up-to-date guidelines (Rudski et al., 20I0). An echocardiography exercise table was used (Ergoselect II 1200; Ergoline; Bitz, Germany) and tilted $35^{\circ}$ backwards and $33^{\circ}$ to the left as used for optimal sampling of signals. The following measurements and derived calculations were collected at rest and during the second minute at every workload: right ventricle (RV) enddiastolic area (RVEDA); RV end-systolic area (RVESA); RV fractional area change [RVFAC $=($ RVEDA-RVESA)/RVEDA $\times 100]$; tricuspid annular plane systolic excursion (TAPSE); peak systolic RV-right atrium (RA) pressure gradient, calculated according to the simplified Bernoulli equation ( $4 \mathrm{~V}^{2} ; \mathrm{V}=$ peak systolic velocity of TR flow in continuous wave Doppler); systolic PAP (sPAP), measured by adding to RV-RA gradient an estimation of RA pressure according to diameter and collapsibility of the inferior vena cava; mean PAP (mPAP) estimated from sPAP as $0.61 \times$ sPAP $+2 \mathrm{mmHg}$ (Chemla et al., 2004); LAP estimated from the ratio of Doppler mitral $\mathrm{E}$ flow velocity wave and tissue Doppler mitral annulus flow (e') early diastolic peak velocity $\left(\mathrm{LAP}=1.9+1.24 \mathrm{E} / \mathrm{e}^{\prime}\right)$; stroke volume (SV) estimated from left ventricle outflow tract (LVOT) area and velocity-time integral (VTI): SV $=\left(3.14 / 4 \times\right.$ LVOT diameter $\left.^{2}\right)$ $x$ VTI; Q calculated as SV $x$ heart rate $(H R)$ and RV tricuspid annulus peak systolic velocity $\left(\mathrm{S}^{\prime}\right)$ measured by pulsed wave tissue Doppler imaging.

The ratio of SPAP to RVESA was taken as surrogate of end-systolic elastance (the gold standard of in vivo load-independent measure of right heart contractility) (Claessen et al., 2016). The adequacy of RVpulmonary arterial (PA) coupling was estimated from the ratio of TAPSE to sPAP (Guazzi et al. 20l8). PVR was calculated as (mPAPLAP)/Q and total PVR (TPR) as mPAP/Q. Each multipoint of the mPAP-Q relationship was fitted to the equation:

mPAP $\left.=\left[(I+\alpha L A P)^{5}+5 \alpha \cdot R_{0} \cdot Q\right){ }^{1 / 5}-I\right] / \alpha$, where $\mathrm{R}_{0}$ is TPR at rest, to calculate a distensibility $\alpha$ index in \% change in resistive vessel diameter, per $\mathrm{mmHg}$ increase in transmural pressure during exercise (Naeije et al., 20I3).

The echocardiographic recordings were stored on optical disks. We previously reported intra-observer variabilities for SPAP and Q estimates as $4.3 \%$ and $4.0 \%$ at rest, and $8.2 \%$ and $7.7 \%$ at maximum exercise, respectively, and inter-observer variabilities of SPAP and Q estimates of $1.9 \%$ and $4.9 \%$ at rest, and $7.9 \%$ and $13.9 \%$ at maximum exercise, respectively (Argiento et al., 20I2). Echocardiographic measurements and analyses were performed blindly.

\section{Lung diffusing capacity measurements}

$D L_{C O}$ and $D L_{N O}$ were measured in the semi-recumbent position at rest and during exercise at $100 \mathrm{~W}$ using a single breath method with automated device for calibrations, mixing of gases and online calculations (Hyp'Air compact; Medisoft; Dinant, Belgium) as previously reported (Simaga et al., 2017). Mixed gas was inspired (40 ppm of NO, 2800 ppm of $\mathrm{CO}, 14 \%$ of helium and $19 \%$ of $\mathrm{O}_{2}$ in nitrogen) with a breath holding time of $4 \mathrm{~s}$, and the composition of expired gas was analyzed with first $0.8 \mathrm{~L}$ of expired gas discarded and in keeping with updated recommendations (Zavorsky et al., 2017). Alveolar volume $\left(V_{A}\right)$ was measured with helium dilution.

The Roughton and Forster (1957) equation states that $\mathrm{I} / \mathrm{DL}=$ $\mathrm{I} / \mathrm{Dm}+\mathrm{I} / \theta \mathrm{Vc}$ where $\mathrm{DL}$ is the lung diffusing capacity for a specific gas, Dm its membrane component, Vc the capillary blood volume and $\theta$ the blood conductance for this gas. Vc can thus be estimated from the two lung diffusing capacity measurements, using $\mathrm{CO}$ and $\mathrm{NO}$ as tracer gases, by solving a system of two equations with two unknowns. The coefficient relating $D_{\mathrm{NO}}$ and $\mathrm{Dm}$ was set at 1.97 according to the solubility and molecular weights of both gases. $\theta \mathrm{NO}$ was set at a finite value of $4.5 \mathrm{ml} \mathrm{NO} / \mathrm{ml}$ blood $/ \mathrm{min} / \mathrm{mmHg}$, as experimentally established (Borland et al., 20l0). Delta Vc was calculated as the difference between $V_{c}$ measured at rest and at $100 \mathrm{~W}$ and represented the increasing of pulmonary capillary volume during exercise.

\section{Cardiopulmonary exercise testing}

The CPET were performed as previously reported (Forton et al., 20।6) with breath by breath measurements of $\mathrm{VO}_{2}$, carbon dioxide production $\mathrm{VCO}_{2}$ and $\mathrm{V}_{\mathrm{E}}$ on a cycle ergometer at progressively increased workload (HypAir; Medisoft; Dinant, Belgium) of 10-30 W/min until volitional fatigue for an optimal test duration between 10 and 12 min for all subjects. $\mathrm{SpO}_{2}$ and $\mathrm{HR}$ were measured continuously. $\mathrm{VO}_{2}$ max was considered to be achieved when two of the following criteria were met: an increase in $\mathrm{VO}_{2}$ of less than $100 \mathrm{ml} / \mathrm{min}$ with a further increase in workload, a respiratory exchange ratio (RER) greater than I.I or age- 
Table I Stress echocardiography in adolescents/young adults conceived by in vitro fertilization (IVF) and in controls. Data are Mean \pm SD.

\begin{tabular}{|c|c|c|c|c|}
\hline \multirow[b]{2}{*}{ Variables } & \multicolumn{2}{|c|}{ REST } & \multicolumn{2}{|c|}{ PEAK } \\
\hline & $\begin{array}{l}\text { IVF } \\
(n=\mid 5)\end{array}$ & $\begin{array}{l}\text { CONTROL } \\
(n=30)\end{array}$ & $\begin{array}{l}\text { IVF } \\
(n=15)\end{array}$ & $\begin{array}{l}\text { CONTROL } \\
(n=30)\end{array}$ \\
\hline mPAP $(\mathrm{mmHg})$ & $16.1 \pm 1.6$ & $16.8 \pm 2.2$ & $30.6 \pm 4.6$ & $30.0 \pm 3.9$ \\
\hline $\mathrm{Q}(\mathrm{L} / \mathrm{min})$ & $5.2 \pm 1.0$ & $5.2 \pm 0.7$ & $14.3 \pm 4.0$ & $15 . \mid \pm 2.6$ \\
\hline $\mathrm{Qi}\left(\mathrm{L} / \mathrm{min} / \mathrm{m}^{2}\right)$ & $3.1 \pm 0.5$ & $3.2 \pm 0.4$ & $8.6 \pm 1.5$ & $9.3 \pm 1.6$ \\
\hline $\mathrm{HR}$ (bpm) & $83 \pm 9$ & $78 \pm 8$ & $174 \pm 18$ & $177 \pm 12$ \\
\hline $\operatorname{LAP}(\mathrm{mmHg})$ & $8.2 \pm 1.5$ & $8.5 \pm 1.0$ & $10.8 \pm 1.3$ & $11.0 \pm 1.2$ \\
\hline PVR (Wood units) & $1.7 \pm 0.3$ & $1.5 \pm 0.3$ & $1.3 \pm 0.2$ & $1.2 \pm 0.2$ \\
\hline $\mathrm{S}^{\prime}(\mathrm{cm} / \mathrm{s})$ & $13.0 \pm 2.0$ & $14.7 \pm 1.4 * *$ & $27.3 \pm 4.7$ & $27.7 \pm 3.5$ \\
\hline TAPSE $(\mathrm{mm})$ & $23.5 \pm 3.3$ & $24.9 \pm 2.2$ & $32.8 \pm 3.4$ & $32.9 \pm 2.7$ \\
\hline RVEDA $\left(\mathrm{cm}^{2}\right)$ & $20.3 \pm 4.7$ & $18.5 \pm 2.3$ & $15.2 \pm 2.1$ & $14.5 \pm 2.0$ \\
\hline $\operatorname{RVESA}\left(\mathrm{cm}^{2}\right)$ & $10.1 \pm 2.4$ & $9.3 \pm 1.2$ & $5.8 \pm 1.2$ & $5.8 \pm 0.8$ \\
\hline RVFAC (\%) & $50.3 \pm 3.9$ & $49.5 \pm 3.0$ & $61.8 \pm 5.5$ & $60.0 \pm 3.6$ \\
\hline $\mathrm{sPAP} / \mathrm{RVESA}\left(\mathrm{mmHg} / \mathrm{cm}^{2}\right)$ & $2.4 \pm 0.6$ & $2.6 \pm 0.3$ & $8.8 \pm 1.7$ & $8.3 \pm 0.9$ \\
\hline TAPSE/sPAP $(\mathrm{mm} / \mathrm{mmHg})$ & $1.2 \pm 0.2$ & $1.2 \pm 0.2$ & $0.7 \pm 0.1$ & $0.8 \pm 0.2$ \\
\hline \multicolumn{5}{|c|}{ SLOPES } \\
\hline & \multicolumn{2}{|c|}{$\operatorname{IVF}(n=15)$} & \multicolumn{2}{|c|}{ CONTROL $(n=30)$} \\
\hline $\mathrm{mPAP}-\mathrm{Q}(\mathrm{mmHg} / \mathrm{L} / \mathrm{min})$ & \multicolumn{2}{|c|}{$1.70 \pm 0.75$} & \multicolumn{2}{|c|}{$1.45 \pm 0.38$} \\
\hline$\alpha(\% / \mathrm{mmHg})$ & \multicolumn{2}{|c|}{$1.2 \pm 0.3$} & \multicolumn{2}{|c|}{$1.5 \pm 0.3^{*}$} \\
\hline
\end{tabular}

predicted maximal HR. The ventilatory threshold (VT) was measured by the $\mathrm{V}$-slope method. The $\mathrm{V}_{\mathrm{E}} / \mathrm{VCO}_{2}$ slope was calculated from the angular coefficient of the $\mathrm{V}_{\mathrm{E}}$ versus $\mathrm{VCO}_{2}$ slope plotted from rest to maximal exercise.

\section{Statistics}

Results are presented as mean \pm SD. Multipoint mPAP-Q relationships were tested for linearity and a Poon adjustment was applied to correct for individual variability (Poon et al., 1988). Repeated measurements were submitted to a 2-way analysis of variance, and paired student $t$-tests applied to compare specific situations when the F-ratio of the analysis of variance reached a $P<0.05$ critical value (Wallenstein et al., 1980). Paired $t$-tests (or Wilcoxon tests when variables were not normally distributed) with Bonferroni adjustment for multiple comparisons were used to compare IVF adolescents/young adults to the mean of the matched pair of controls.

\section{Results}

\section{Clinical examination}

There were no differences between IVF adolescents/young adults and controls in sex distribution, age, weight, height, BSA and BMI showing adequate matching.

\section{Exercise stress echocardiography of the pulmonary circulation and the right ventricle}

At maximal exercise, sufficient quality echocardiographic images until maximal exercise were obtained in 42 of the 45 subjects. Except for lower $S^{\prime}$ in IVF adolescents/young adults, there were no differences at rest or at maximum exercise in HR, BP, mPAP, Q, PVR, mPAP-Q slope, TAPSE, RVEDA, RVESA, RVFAC, TAPSE/sPAP, sPAP/RVESA and E' (Table I). The coefficient of pulmonary vascular distensibility $\alpha$ was $20 \%$ lower in IVF adolescents compared to controls (Table I). Individual and averaged mPAP-Q plots are illustrated in Figure I, showing decreased curvilinearity in IVF adolescents/young adults.

\section{Lung diffusing capacity}

There were no differences in $V_{A}, D L_{N O}, D L_{C O}, D m, V_{c}$ and $D L_{N O} / D L_{C O}$ ratio at rest and at an exercise level of $100 \mathrm{~W}$ between IVF adolescents/young adults and controls (Table II). However, the increase of $V_{c}$ observed during exercise (delta $V_{c}$ ) was reduced by $20 \%$ in the IVF children compared to matched controls (Table II, Fig. 2).

\section{Cardiopulmonary exercise test}

Both IVF adolescents/young adults and controls reached a $\mathrm{VO}_{2}$ max with a maximum RER $>$ I.I. There were no differences in maximum 


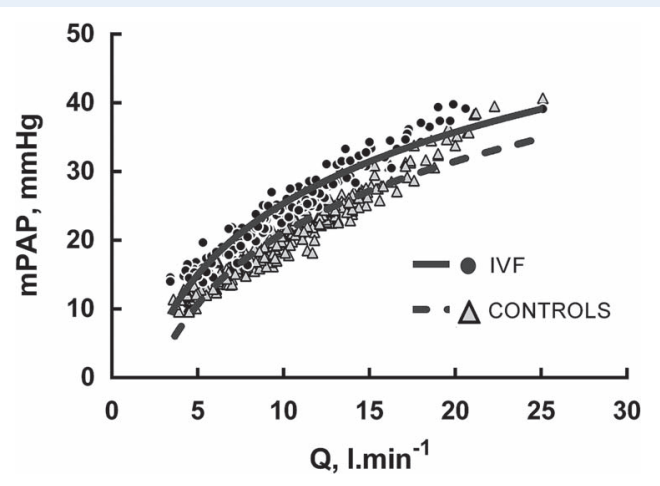

Figure I Poon-adjusted mean PAP (mPAP) versus cardiac output $(Q)$ relationships in $I 5$ adolescents conceived by IVF and $\mathbf{3 0}$ matched controls. The curvilinearity of the relationships was decreased in IVF adolescents.

Table II Lung diffusing capacity in adolescents/young adults conceived by in vitro fertilization (IVF) and in controls. Data are Mean \pm SD.

\begin{tabular}{|c|c|c|}
\hline & $\begin{array}{l}\text { IVF } \\
(N=15)\end{array}$ & $\begin{array}{l}\text { CONTROL } \\
(\mathbf{N}=\mathbf{3 0})\end{array}$ \\
\hline $\mathrm{V}_{\mathrm{A}}(\mathrm{L})$ & $5.4 \pm 1.8$ & $5.0 \pm 1.1$ \\
\hline $\mathrm{DL}_{\mathrm{NO}}(\mathrm{mL} / \mathrm{min} \cdot \mathrm{mmHg})$ & $147 \pm 39$ & $149 \pm 29$ \\
\hline $\mathrm{DL}_{\mathrm{CO}}(\mathrm{mL} / \mathrm{min} \cdot \mathrm{mmHg})$ & $29 \pm 7$ & $30 \pm 5$ \\
\hline $\mathrm{Dm}(\mathrm{mL} / \mathrm{mmHg} / \mathrm{M})$ & $149 \pm 49$ & $155 \pm 40$ \\
\hline $\mathrm{Vc}(\mathrm{mL})$ & $69 \pm 14$ & $67 \pm 11$ \\
\hline $\mathrm{DL}_{\mathrm{NO}} / \mathrm{DL}_{\mathrm{CO}}$ & $5.0 \pm 0.4$ & $5.0 \pm 0.2$ \\
\hline $\mathrm{DL}_{\mathrm{CO}} / \mathrm{V}_{\mathrm{A}}(\mathrm{mL} / \min \cdot \mathrm{mmHg} \cdot \mathrm{L})$ & $5.6 \pm 0.9$ & $\begin{array}{l}6.0 \pm 0.6 \\
6\end{array}$ \\
\hline \multicolumn{3}{|l|}{ Exercise $(100 \mathrm{~W})$} \\
\hline $\mathrm{V}_{\mathrm{A}}(\mathrm{L})$ & $5.8 \pm 1.5$ & $5.6 \pm 1.2$ \\
\hline $\mathrm{DL}_{\mathrm{NO}}(\mathrm{mL} / \mathrm{min} \cdot \mathrm{mmHg})$ & $174 \pm 3 \mid$ & $177 \pm 29$ \\
\hline $\mathrm{DL}_{\mathrm{CO}}(\mathrm{mL} / \mathrm{min} \cdot \mathrm{mmHg})$ & $37 \pm 7$ & $38 \pm 5$ \\
\hline $\mathrm{Dm}(\mathrm{mL} / \mathrm{mmHg} / \mathrm{M})$ & $160 \pm 31$ & $168 \pm 36$ \\
\hline$V_{c}(m L)$ & $87 \pm 14$ & $91 \pm 14$ \\
\hline $\mathrm{DL}_{\mathrm{NO}} / \mathrm{DL} \mathrm{LO}_{\mathrm{CO}}$ & $4.7 \pm 0.3$ & $4.7 \pm 0.3$ \\
\hline $\mathrm{DL}_{\mathrm{CO}} / \mathrm{V}_{\mathrm{A}}(\mathrm{mL} / \mathrm{min} \cdot \mathrm{mmHg} \cdot \mathrm{L})$ & $6.6 \pm 0.8$ & $7.0 \pm 1.0$ \\
\hline $\mathrm{HR}$ at $100 \mathrm{~W}(\mathrm{bpm})$ & $148 \pm 14$ & $153 \pm 15$ \\
\hline$\Delta \mathrm{V}_{\mathrm{C}}(\mathrm{ml})$ & $16.7 \pm 8.4$ & $20.7 \pm 4.3^{*}$ \\
\hline
\end{tabular}

VA: alveolar volume; $\mathrm{DL}_{\mathrm{NO}}$ : lung diffusing capacity for nitric oxide; $\mathrm{DL}_{\mathrm{CO}}$ : lung diffusing capacity for carbon monoxide; Dm: alveolo-capillary membrane component of DL; Vc: pulmonary capillary blood volume; HR: heart rate. ${ }^{*} \mathrm{P}<0.05$ IVF vs Control.

$\mathrm{VO}_{2}$, workload, $\mathrm{BP}, \mathrm{SpO}_{2}, \mathrm{HR}, \mathrm{O}_{2}$ pulse and $\mathrm{V}_{\mathrm{E}}$. The $\mathrm{V}_{\mathrm{E}} / \mathrm{VCO}_{2}$ slope and $\mathrm{VT}$ were not different (Table III). There was no correlation between the distensibility factor $\alpha$ and maximum $\mathrm{VO}_{2}(r=0.11, P=0.2)$.

\section{Hypoxic testing}

In normoxia at rest, IVF adolescents/young adults and controls had no different parameters of the pulmonary circulation and RV structure

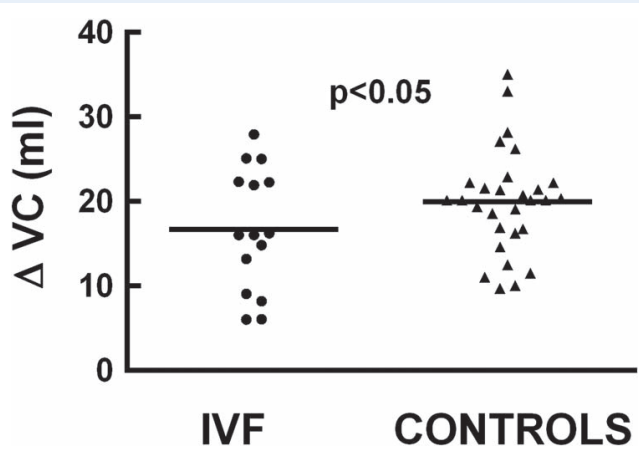

Figure 2 Exercise-induced increase in pulmonary capillary blood volume (Vc) in I 5 adolescents conceived by IVF versus 30 matched controls. Mean values are shown by horizontal bars. Two of the controls had a markedly larger increase in Vc. After removing them, the difference between IVF adolescents and controls remained significant. Thus, exercise-induced increase in $\mathrm{Vc}$ was blunted in IVF adolescents.

Table III Cardio-Pulmonary Exercise Testing in adolescents/young adults conceived by in vitro fertilization (IVF) and in controls. Data are Mean \pm SD.

\begin{tabular}{|c|c|c|}
\hline Variables & $\begin{array}{l}\text { IVF } \\
(n=\mid 5)\end{array}$ & $\begin{array}{l}\text { CONTROL } \\
(n=s 30)\end{array}$ \\
\hline SBP rest $(\mathrm{mmHg})$ & $104 \pm 13$ & $108 \pm 12$ \\
\hline DBP rest $(\mathrm{mmHg})$ & $67 \pm 8$ & $68 \pm 8$ \\
\hline SBP $\max (\mathrm{mmHg})$ & $178 \pm 27$ & $178 \pm 14$ \\
\hline DBP $\max (\mathrm{mmHg})$ & $74 \pm 15$ & $73 \pm 13$ \\
\hline $\mathrm{HR} \max (\mathrm{bpm})$ & $192 \pm 7$ & $192 \pm 9$ \\
\hline $\mathrm{VO}_{2} \max (\mathrm{I} / \mathrm{min})$ & $2.6 \pm 0.7$ & $2.5 \pm 0.4$ \\
\hline $\mathrm{VO}_{2} \max (\mathrm{ml} / \mathrm{kg} / \mathrm{min})$ & $44 \pm 9$ & $45 \pm 7$ \\
\hline W (Watts) & $187 \pm 48$ & $188 \pm 30$ \\
\hline$V_{E} \max (I / \min )$ & $105 \pm 34$ & $100 \pm 13$ \\
\hline $\mathrm{SpO}_{2} \max (\%)$ & $96 \pm 2$ & $95 \pm 2$ \\
\hline RER & $1.20 \pm 0.08$ & $1.16 \pm 0.04$ \\
\hline $\mathrm{O}_{2}$ Pulse $\max (\mathrm{bpm} / \mathrm{ml} / \mathrm{min})$ & $13.5 \pm 3.4$ & $|3| \pm 2.8$. \\
\hline \multicolumn{3}{|c|}{ Ventilatory Threshold } \\
\hline $\mathrm{VO}_{2}(\mathrm{ml} / \mathrm{kg} / \mathrm{min})$ & $27 \pm 6$ & $29 \pm 5$ \\
\hline $\mathrm{V}_{\mathrm{E}} / \mathrm{VCO}_{2}$ & $30.1 \pm 3.5$ & $\begin{array}{r}29.8 \pm 2.2 \\
\ldots\end{array}$ \\
\hline \multicolumn{3}{|c|}{ Slopes } \\
\hline $\mathrm{V}_{\mathrm{E}} / \mathrm{VCO}_{2}$ & $31.5 \pm 3.2$ & $30.2 \pm 3.0$ \\
\hline $\mathrm{VO}_{2} / \mathrm{W}(\mathrm{ml} / \mathrm{kg} / \mathrm{min} / \mathrm{W})$ & $10.9 \pm 1.8$ & $10.6 \pm 0.7$ \\
\hline $\mathrm{HR} / \mathrm{W}(\mathrm{b} / \mathrm{min} / \mathrm{W})$ & $4.9 \pm 1.1$ & $5.41 \pm 1.19$ \\
\hline
\end{tabular}

or function. The RV-PA coupling parameters TAPSE/sPAP and sPAP/RVESA were not different. Hypoxia increased mPAP, Q, HR, PVR and sPAP/RVESA, and decreased TAPSE/sPAP. These changes were not different in IVF adolescents/young adults and matched controls. 
Table IV Hypoxic testing in adolescents/young adults conceived by in vitro fertilization (IVF) and in controls. Data are Mean \pm SD.

\begin{tabular}{|c|c|c|c|c|c|c|}
\hline \multirow[t]{2}{*}{ Variables } & \multicolumn{2}{|c|}{ Normoxia } & \multicolumn{2}{|c|}{ Hypoxia 15 min } & \multicolumn{2}{|c|}{ Hypoxia 30 min } \\
\hline & IVF (8) & Control (8) & IVF (8) & Control (8) & IVF (8) & Control (8) \\
\hline mPAP $(\mathrm{mmHg})$ & $14.9 \pm 0.8$ & $15.6 \pm 1.8$ & $18.9 \pm 2.2^{\$ \$ \$}$ & $19.5 \pm 1.8^{\$}$ & $20.3 \pm 1.5^{\$ \$ \$}$ & $20.1 \pm 2.2^{\$ \$}$ \\
\hline $\mathrm{Q}(\mathrm{I} / \mathrm{min})$ & $5.0 \pm 0.6$ & $4.7 \pm 0.5$ & $6.4 \pm 1.6$ & $6.1 \pm 1.8$ & $7.1 \pm 1.1^{\$}$ & $6.3 \pm 1.5^{\$}$ \\
\hline $\mathrm{HR}(\mathrm{b} / \mathrm{min})$ & $78 \pm 13$ & $73 \pm 14$ & $91 \pm 9$ & $90 \pm 12$ & $93 \pm 7$ & $90 \pm 12$ \\
\hline $\mathrm{SpO}_{2}(\%)$ & $99 \pm 1$ & $98 \pm 1$ & $67 \pm 3$ & $71 \pm 1$ & $65 \pm 2$ & $66 \pm 2$ \\
\hline LAP (mmHg) & $7.9 \pm 1.3$ & $7.7 \pm 1.3$ & $8.2 \pm 2.6$ & $7.6 \pm 1.2$ & $8.1 \pm 1.3$ & $7.6 \pm 0.7$ \\
\hline PVR (Wood Unit) & $1.4 \pm 0.3$ & $1.7 \pm 0.3^{*}$ & $1.8 \pm 0.6$ & $2.2 \pm 0.5$ & $1.7 \pm 0.5$ & $2.0 \pm 0.5$ \\
\hline $\mathrm{S}^{\prime}(\mathrm{cm} / \mathrm{s})$ & $\mid 4.1 \pm 2.1$ & $13.6 \pm 1.9$ & $16.1 \pm 1.7$ & $16.2 \pm 2.2$ & $15.4 \pm 2.0$ & $15.5 \pm 2.5$ \\
\hline TAPSE (mm) & $25.9 \pm 2.6$ & $23.7 \pm 4.4$ & $27.2 \pm 3.1$ & $25.0 \pm 4.1$ & $28.4 \pm 2.8$ & $25.1 \pm 4.3$ \\
\hline RVEDA $\left(\mathrm{cm}^{2}\right)$ & $19.6 \pm 3.9$ & $19.5 \pm 4.5$ & $19.5 \pm 4.7$ & $20.0 \pm 5.8$ & $19.3 \pm 4.0$ & $18.3 \pm 4.9$ \\
\hline RVESA $\left(\mathrm{cm}^{2}\right)$ & $9.4 \pm 2.0$ & $9.5 \pm 2.3$ & $9.1 \pm 2.7$ & $9.0 \pm 2.5$ & $9.0 \pm 2.3$ & $8.2 \pm 2.4$ \\
\hline RVFAC (\%) & $51.9 \pm 2.2$ & $51.2 \pm 3.7$ & $53.8 \pm 4.1$ & $54.5 \pm 4.7$ & $53.4 \pm 5.9$ & $55.3 \pm 6.6$ \\
\hline $\begin{array}{l}\text { sPAP/RVESA } \\
\left(\mathrm{mmHg} / \mathrm{cm}^{2}\right)\end{array}$ & $2.3 \pm 0.6$ & $2.5 \pm 0.6$ & $2.9 \pm 0.7$ & $3.4 \pm 0.8$ & $3.5 \pm 0.9^{\$}$ & $3.9 \pm 1.5^{\$}$ \\
\hline $\begin{array}{l}\text { TAPSE/sPAP } \\
(\mathrm{mm} / \mathrm{mmHg})\end{array}$ & $\mathrm{I} .4 \pm 0.2$ & $1.2 \pm 0.3$ & $1.1 \pm 0.2^{\$ \$ \$}$ & $1.0 \pm 0.1$ & $1.1 \pm 0.1^{\$ \$ \$}$ & $1.0 \pm 0.2$ \\
\hline Alpha $\alpha(\% / \mathrm{mmHg})$ & $1.82 \pm 0.26$ & $1.61 \pm 0.32$ & $0.97 \pm 0.21^{\$ \$ \$}$ & $1.01 \pm 0.27^{\$ \$}$ & $0.99 \pm 0.30^{\$ \$ \$}$ & $0.95 \pm 0.30^{\$ \$}$ \\
\hline
\end{tabular}

Abbreviations: see Table II. ${ }^{\$} \mathrm{p}<0.05 ;{ }^{\$ \$} \mathrm{p}<0.0$ I; ${ }^{\$ \$} \mathrm{p}<0.00$ I Hypoxia versus normoxia. ${ }^{*} \mathrm{p}<0.05$ IVF versus controls.

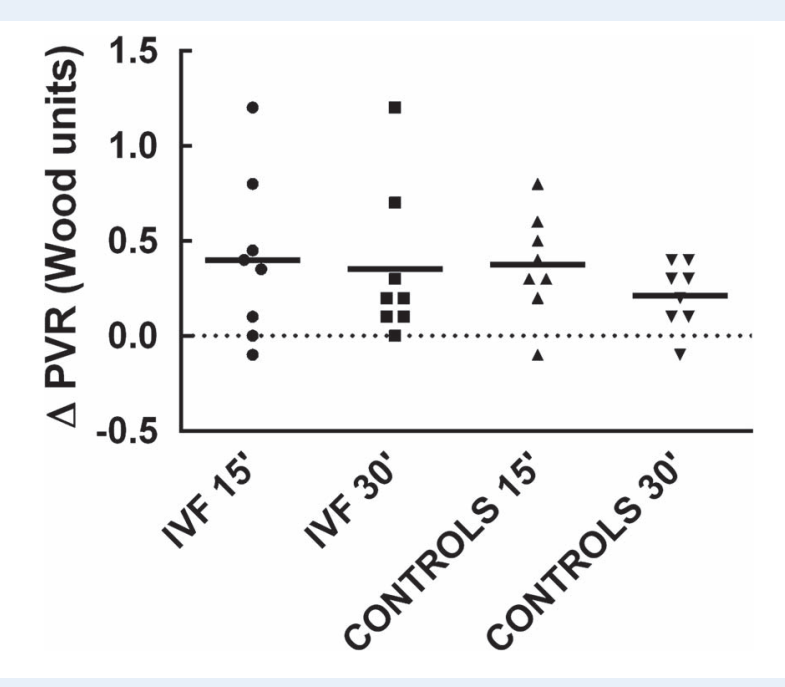

Figure 3 Increase in pulmonary vascular resistance ( $\triangle P V R)$ induced by $15 \mathrm{~min}$ and $30 \mathrm{~min}$ hypoxic breathing (fraction of inspired oxygen 12\%) in eight adolescents conceived by IVF versus eight matched controls. Mean values are shown by horizontal bars. Acute hypoxic vasoconstriction was not different in IVF adolescents and in controls.

Hypoxia-induced increase in PVR was not different in IVF adolescents/young adults and controls (Table IV, Fig. 3).

\section{Discussion}

The present results suggest that adolescents/young adults conceived by IVF/ICSI have slight alterations in pulmonary vascular distensibility as assessed by two entirely different methods, i.e. exercise stress echocardiography and lung diffusing capacity measurements, suggesting decreased pulmonary vascular reserve, but with no associated impact on RV function or aerobic exercise capacity.

\section{Pulmonary vascular distensibility}

Exercise is normally associated with a decreased PVR, which is explained by vascular recruitment at initial increase in $\mathrm{Q}$ and vascular distension at higher $\mathrm{Q}$ when the pulmonary circulation is entirely perfused during exercise (Kovacs et al., 20I2; Naeije et al., 20I3). In fully recruited lungs, the PVR equation can be improved by the incorporation of a resistive vessel distensibility coefficient $\alpha$, which defines the percentage of increase in resistive vessel diameter per mmHg increase in pulmonary vascular pressure (Linehan et al., 1992). Invasive and non-invasive studies have shown that $\alpha$ is normally between I and $2 \% / \mathrm{mmH}$, higher in young healthy women, and lower with aging or chronic hypoxic exposure (Reeves et al., 2005; Naeije et al., 2013; Lau et al. 2016). Non-invasive studies, using the similar echocardiographic determination of $\alpha$ have been able to detect subtle alterations in pulmonary vascular function in mild to moderate systemic hypertension with normal left heart function (Vriz et al., 20I5), in male subjects of Sub-Saharan African ancestry compared to Caucasian controls (Simaga et al., 2015) and after inhalation of diesel exhaust (Wauters et al., 20I5). Decreased $\alpha$ in the present study thus likely indicates a decreased pulmonary vascular distensibility in IVF adolescents.

In healthy volunteers, $\alpha$ has been shown to be correlated to $\mathrm{VO}_{2}$ max, suggesting that a more distensible pulmonary circulation allows a higher aerobic exercise capacity to be reached (Lalande et al., 20 I2; Simaga et al., 2015). In heart failure patients, $\alpha$ has been shown to 
be positively correlated to RV ejection fraction and to independently predict peak $\mathrm{VO}_{2}$ (Malhotra et al., 2016). In the present study, $\alpha$ was not correlated to $\mathrm{VO}_{2}$ max. Furthermore, in spite of a significant decrease in $\alpha, \mathrm{VO}_{2}$ max was not different in the IVF adolescents/young adults compared to controls. This apparent discrepancy with previous studies is to be explained by insufficient stiffening of the pulmonary vessels with $\alpha$ reduced by only $20 \%$, but compared with high-normal values in adolescent control that would not be enough for a sensitive decrease in RV afterload. Moreover, coupling of RV function to the pulmonary circulation is only one of multiple other determinants of aerobic exercise capacity, which may be affected by differences in age, sex and race (Simaga et al. 20I5, Malhotra et al., 20I6), and evolve in still incompletely understood fashion from adolescence to adulthood.

\section{Right ventricular function}

Possible long-term consequences of IVF and/or effects of decreased pulmonary vascular distensibility on the RV function were explored in the present study by echocardiographic measurements of systolic function such as TAPSE, $S^{\prime}$ and FAC, or RV dimensions such as RVESA and RVEDA, and TAPSE/sPAP or sPAP/RVESA as more elaborated echocardiographic indices of RV contractility and its coupling to the pulmonary circulation.

None of resting or exercise stress echocardiographic measurements of the RV was different in IVF adolescents/young adults compared to controls, suggesting that the lower distensibility observed in the IVF group is not sufficient to affect RV function and its coupling to the pulmonary circulation. Longitudinal studies are needed to confirm this observation.

The TAPSE/sPAP ratio was initially conceived as an estimate of RV myocardial length-tension relationship (Guazzi et al., 2013) and subsequently rather viewed as indirect estimate of RV-PA coupling (Guazzi et al., 20I8). The TAPSE/sPAP ratio has been shown to be a potent predictor of outcome in heart failure (Guazzi et al., 2013; Guazzi et al., 2018) or in PA hypertension (Tello et al., 2018). In the present study, the TAPSE/sPAP decreased during exercise, and also during hypoxic breathing. Previous studies have shown that the TAPSE/sPAP ratio decreases with exercise and aging but definition of limits of normal are unknown (D'Alto et al., 20I7).

The sPAP/RVESA ratio may be closer to gold standard loadindependent end-systolic elastance to assess RV contractility (Claessen et al., 2016). In the present study, sPAP/RVESA did not change or increased during exercise or hypoxia, in keeping with the basic notion of RV systolic function adaptation to acute increase in afterload (Vonk Noordegraaf, 2017).

Unchanged RV dimensions during hypoxic breathing in the present study contrast with increased RVESA and RVEDA reported in ART children exposed to the moderate altitude of $3454 \mathrm{~m}$ (von Arx et al., 20I5). In that study, the trans-tricuspid gradient was on average of $32 \mathrm{mmHg}$ in controls and $38 \mathrm{mmHg}$ in IVF children, with no differences in estimated right and LAPs and cardiac output, suggesting enhanced hypoxic vasoconstriction even though at this relatively moderate altitude, $\mathrm{SpO}_{2}$ decreased only to an average of $89.4 \%$ (von Arx et al., 20I5). In the present study, much lower $\mathrm{SpO}_{2}$ down to $60-70 \%$ was not associated with different PVR in IVF adolescents/young adults and in controls. The reasons for these discrepancies are unclear. Other factors than just hypoxia-induced vasoconstriction may affect the pul- monary circulation during 2 days of altitude exposure compared to an acute normobaric hypoxic tests. A type II error is also possible, as in the present study, only eight IVF adolescents/young adults underwent an acute hypoxic challenge. In general, hypoxic exposure increases PVR by a small and variable amount (Soria et al., 2016) so that small group differences may not be apparent in all studies.

\section{Lung diffusion capacity and pulmonary capillary blood volume}

It has previously been shown that higher aerobic exercise capacity is associated with higher $\mathrm{DL}_{\mathrm{NO}}$ and $\mathrm{DL}_{\mathrm{CO}}$ at rest and during exercise, in normoxic and in hypoxic conditions (Johnson et al., 1960; Dempsey et al., 197I; Hsia et al., I 995; Lalande et al., 20 I2; Pavalescu et al., 20 I3; Simaga et al., 2017). Interestingly, $V_{c}$ derived from $\mathrm{DL}_{\mathrm{co}}$ predicted $\mathrm{VO}_{2}$ max more tightly than $\mathrm{Dm}$ or $\mathrm{DL}_{\mathrm{NO}}$ in keeping with the concept that a greater 'pulmonary vascular reserve', described by larger $V_{c}$ and lower PVR, allows higher maximal right ventricular output (Lalande et al., 2012; Simaga et al., 2017). In the present study, there were no differences in lung diffusing capacity measurements and derived calculations in IVF adolescents/young adults versus controls. A difference emerged in terms of exercise-induced increase in $V_{c}$, yet with no measurable impact on $\mathrm{VO}_{2}$ max. This may be explained by the fact that the change in Vc occurred in a range of high-normal values, so that other determinants of aerobic exercise capacity would have remained predominant. However, both $\alpha$ calculations and measured changes in Vc point at a difference in pulmonary vascular reserve between IVF subjects and controls. Because of the large number of measurements, both findings could have occurred by chance, but not likely so if pointing at the same physiologic characteristic by two completely independent methods, and in keeping with differently shown altered vascular function in IVF offspring.

\section{Aerobic exercise capacity}

Our results showed for the first time that the previously and currently observed differences in the pulmonary circulation in ART children does not seem to impact the aerobic exercise capacity. Indeed, according to prediction equation of $\mathrm{VO}_{2} \max$ (Cooper et al., 1984; Ten Harkel et al., 20I I; Cooper et al., 20।4), in the present study the IVF adolescents/young adults reached $108 \%$ of the predictive values for $102 \%$ of those values in the controls. This is of interest as $\mathrm{VO}_{2}$ max is related to functional capacity and has been shown to be a strong and independent predictor of all-cause and disease-specific mortality regardless of sex and race.

\section{Systemic BP}

It is noticeable that in the present study, resting as well as exercise systolic and diastolic BP were not different in IVF adolescents and in controls. Increased BP in the presence or not of increased body weight has been reported in IVF children, but inconstantly so (Guo et al., 20 17; Pinborg et al., 20 19). Mice conceived by ART present with hypertension and this is associated with a $25 \%$ decrease in life expectancy (Rexhaj et al., 20 I3). However, BP was not different in 65 ART children, 21 of them conceived by IVF, compared to 57 controls in spite of abnormal flow-induced responses, increased carotid intima-media 
thickness and increased pulse wave velocity (Scherrer et al., 20I2). But in a recent 5-year follow-up of that study, 24-hour ambulatory BP monitoring showed significant average increases in systolic and diastolic BP by 4 and $2 \mathrm{mmHg}$, respectively, together with increased BP variability, and confirmed previously reported measurements of increased systemic vascular stiffness (Meister et al., 20 I 8). A recent meta-analysis confirmed that children conceived by IVF intra-cytoplasmic sperm injection manifest a minor yet statistically significant increase in BP without the clustering of increased BMI or impaired lipid metabolism by early adulthood (Guo et al., 2017). Thus, the absence of demonstrable increase in BP in the present study was probably explained by the small sample size and signal-to-noise ratio.

Why altered vascular function may occur in IVF (or ART in general) offspring is not yet entirely understood. Currently the most likely explanation rests on epigenetic mechanisms leading to altered methylation at the promotor gene encoding endothelial NO synthase (Celermajer et al., 2012; Scherrer et al., 20I5; Pinborg et al., 2019). Major epigenetic events are indeed taking place during early embryogenesis and altered imprinted gene expression has been observed in buccal cell DNA and placenta from children born following IVF compared to children conceived spontaneously (Whitelaw et al., 20I4; Choux et al., 20I8). It is still not clear whether differences observed in the outcomes of IVF children compared to those spontaneously conceived are related to the altered maternal endocrine environment resulting from the ovarian stimulation, to the in vitro embryo culture or to pre-existing parental characteristics (Scherrer et al., 2012; Kuiper et al., 2017; Pereira et al., 2017; Goisis et al., 2019).

\section{Limitations}

There are several limitations to the present findings. Our IVF cohort was small, and thus type I or II errors could have occurred in spite of careful matching of each case with two controls. In order to limit variables related to pregnancy and neonatal outcome, we selected only adolescents/young adults born after fresh embryo transfer, as singletons, in term pregnancies ( $\geq 37$ weeks gestation). However, no adjustment could be done for other parameters such as the ovarian stimulation protocol, the maximal level of estradiol and the culture media.

There is always a concern about possible insufficient precision of echocardiographic measurements of the pulmonary circulation (Rudski et al., 2018); however, non-invasive and invasive studies report on the same average values (D'Alto et al. 20I3). Diffusion measurement, following the recent standardization recommendations, are known to have acceptable intra-session (within a given testing session) and intersession (between sessions, or between days) variability for the $D L_{N O}$ and $\mathrm{DLCO}_{\mathrm{CO}}$ in absolute numbers. Moreover, the likelihood to see the same physiologic characteristic emerging from two blindly analyzed independent measurements is very low. The evaluated subjects were born between 1994 and 2007. The technology of IVF has evolved over the years, so that it is not certain that the presently reported subtle changes will be reproducible in the future (Pinborg et al., 2019).

\section{Clinical impact and future research}

The present study is in keeping with previously reported pulmonary vascular dysfunction in IVF adolescents/young adults. Adolescents con- ceived by IVF appear to have slight but significant decreased pulmonary vascular reserve but with no associated alteration of RV function or aerobic exercise capacity. The present results may be reassuring as the observed differences in vascular distensibility are small, within the limits of normal and without subsequent cardiac or functional consequences. Resting or exercise echocardiographic measurements of the RV were similar in IVF adolescents/young adults compared to controls, suggesting that the lower distensibility observed in the IVF group is not sufficient to affect RV function and its coupling to the pulmonary circulation. However, the long-term prognostic relevance of a slight decrease in pulmonary vascular distensibility in IVF offspring cannot be evaluated as currently the vast majority of these subjects are still children, adolescents or young adults. This emphasizes the importance of prospective large scale and long-term follow-up of ART offspring in order to gain more insight into their cardiovascular health. In addition to the variables related to the ovarian stimulation and in vitro culture, long-term follow-up studies will have to face increasing confounding lifestyle and environmental factors. Ensuring and monitoring the health of children conceived through IVF/ICSI is of paramount importance.

In conclusion, the present results suggest that adolescents/young adults conceived by IVF/ICSI have slight alterations in pulmonary vascular distensibility with no right ventricular or exercise capacity alteration but unknown long-term impact.

\section{Acknowledgements}

We thank Chantal Deleau from the Fertility Clinic, Erasmus University Hospital, Brussels for technical support.

\section{Authors' roles}

Significant manuscript writer: KF/AD/RN/VF. Significant manuscript reviewer/reviser: KF/YM/BP/SC/AD/RN/VF. Concept and design: KF/YM/BP/SC/AD/RN/VF. Data acquisition: KF/YM/BP/SC. Data analysis and interpretation: KF/YM/BP/SC/AD/RN/VF. Statistical expertise: KF/VF/RN.

\section{Funding}

Dr Caravita was supported by an European Respiratory Society, Pulmonary Arterial Hypertension short term research training fellowship (STRTF20 I4-5264). Dr Pezzuto was funded by an Italian Society of cardiology grant. Dr Motoji was supported by a grant from the Cardiac Surgery Funds, Belgium.

\section{Conflicts of interest}

The authors have no conflicts of interests to declare.

\section{References}

Argiento P, Vanderpool RR, Mule M, Russo MG, D’Alto M, Bossone E, Chesler NC, Naeije R. Exercise stress echocardiography of the pulmonary circulation: limits of normal and sex differences. Chest 2012; | 42: | I58-1165.

von Arx R, Allemann Y, Sartori C, Rexhaj E, Cerny D, de Marchi SF, Soria R, Germond M, Scherrer U, Rimoldi SF. Right ventricular 
dysfunction in children and adolescents conceived by assisted reproductive technologies. J Appl Physiol 2015; I I 8: 1200-1206.

Borland CD, Dunningham H, Bottrill F, Vuylsteke A, Yilmaz C, Dane DM, Hsia CC. Significant blood resistance to nitric oxide transfer in the lung. J Appl Physiol 2010;1 108:1052-1060.

Calhaz-Jorge C, Feki A, Farquharson R. European view of subspecialty training on behalf of the European Society of Human Reproduction and Embryology (ESHRE). Fertil Steril 20I 5; 104:8-II.

Celermajer DS. Manipulating nature: might there be a cardiovascular price to pay for the miracle of assisted conception. Circulation 2012; I 25: 1832-1834.

Chemla D, Castelain V, Humbert M, Hébert JL, Simonneau G, Lecarpentier $Y$, Hervé P. New formula for predicting mean pulmonary artery pressure using systolic pulmonary artery pressure. Chest 2004; 1 26:1313-1317.

Choux C, Binquet C, Carmignac V, Bruno C, Chapusot C, Barberet J, Lamotte M, Sagot P, Bourc'his D, Fauque P. The epigenetic control of transposable elements and imprinted genes in newborns is affected by the mode of conception: ART versus spontaneous conception without underlying infertility. Hum Reprod 2018;33: $33 \mathrm{I}-340$.

Claessen G, La Gerche A, Voigt JU, Dymarkowski S, Schnell F, Petit T, Willems R, Claus P, Delcroix M, Heidbuchel H. Accuracy of echocardiography to evaluate pulmonary vascular and RV function during exercise. JACC Cardiovasc Imaging 2016;9:532-543.

Cooper DM, Weiler-Ravell D. Gas exchange response to exercise in children. Am Rev Respir Dis 1984; I 29:S47-S48.

Cooper DM, Leu S-Y, Galassetti P, Radom-Aizik S. Dynamic interactions of gas exchange, body mass, and progressive exercise in children. Med Sci Sports Exerc 2014;46:877-886.

D'Alto M, Romeo E, Argiento P, D’Andrea A, Vanderpool R, Correra A, Bossone E, Sarubbi B, Calabrò R, Russo MG et al. Accuracy and precision of echocardiography versus right heart catheterization for the assessment of pulmonary hypertension. Int J Cardiol 2013; 1 68:4058-4062.

D'Alto M, Pavelescu A, Argiento P, Romeo E, Correra A, Di Marco GM, D’Andrea A, Sarubbi B, Russo MG, Naeije R. Echocardiographic assessment of right ventricular contractile reserve in healthy subjects. Echocardiography 2017;34:61-68.

Dempsey JA, Reddan WG, Birnbaum ML, Forster HV, Thoden JS, Grover RF, Rankin J. Effects of acute through life-long hypoxic exposure on exercise pulmonary gas exchange. Respir Physiol 197I; 13:62-89.

Forton K, Motoji Y, Deboeck G, Faoro V, Naeije R. Effects of body position on exercise capacity and pulmonary vascular pressure-flow relationships. J Appl Physiol 2016; I 2: I I I5-1 | 20.

Goisis A, Remes H, Martikainen P, Klemetti R, Myrskylä M. Medically assisted reproduction and birth outcomes: a within-family analysis using Finnish population registers. Lancet 2019;393:1225-1232.

Guazzi M. Use of TAPSE/PASP ratio in pulmonary arterial hypertension: an easy shortcut in a congested road. Int J Cardiol 2018; 266:242-244.

Guazzi M, Bandera F, Pelissero G, Castelvecchio S, Menicanti L, Ghio S, Temporelli PL, Arena R. Tricuspid annular plane systolic excursion and pulmonary arterial systolic pressure relationship in heart failure: an index of right ventricular contractile function and prognosis. Am J Physiol Heart Circ Physiol 2013;305:HI373-HI38I.
Guo XY, Liu XM, Jin L, Wang TT, Ullah K, Sheng JZ, Huang HF. Cardiovascular and metabolic profiles of offspring conceived by assisted reproductive technologies: a systematic review and metaanalysis. Fertil Steril 2017;107:622-631.

Hsia CC, McBrayer DG, Ramanathan M. Reference values of pulmonary diffusing capacity during exercise by a rebreathing technique. Am J Respir Crit Care Med 1995; I 52:658-665.

Johnson RL Jr, Spicer WS, Bishop JM, Forster RE. Pulmonary capillary blood volume, flow and diffusing capacity during exercise. J Appl Physiol 1960; 15:893-902.

Kovacs G, Olschewski A, Berghold A, Olschewski H. Pulmonary vascular resistances during exercise in normal subjects: a systematic review. Eur Respir J 2012;39:319-328.

Kuiper D, Hoek A, la Bastide-van Gemert S, Seggers J, Mulder DJ, Haadsma M, Heineman MJ, Hadders-Algra M. Cardiovascular health of 9-year-old IVF offspring: no association with ovarian hyperstimulation and the in vitro procedure. Hum Reprod 2017;32:2540-2548.

La Gerche A, Maclsaac AL, Burns AT, Mooney DJ, Inder WJ, Voigt JU, Heidbüchel $\mathrm{H}$, Prior DL. Pulmonary transit of agitated contrast is associated with enhanced pulmonary vascular reserve and right ventricular function at exercise. J Appl Physiol 20 10; 1 09: I307-1317.

Lalande S, Yerly P, Faoro V, Naeije R. Pulmonary vascular distensibility predicts aerobic capacity in healthy individuals. J Physiol 2012; 590:4279-4288.

Lau EM, Chemla D, Godinas L, Zhu K, Sitbon O, Savale L, Montani D, Jaïs $X$, Celermajer DS, Simonneau G. Loss of vascular distensibility during exercise is an early hemodynamic marker of pulmonary vascular disease. Chest 2016; 149:353-36।.

Linehan JH, Haworth ST, Nelin LD, Krenz GS, Dawson CA. A simple distensible vessel model for interpreting pulmonary vascular pressure-flow curves. J Appl Physiol 1992;73:987-994.

Maggiorini M, Mélot C, Pierre S, Pfeiffer F, Greve I, Sartori C, Lepori M, Hauser M, Scherrer U, Naeije R. High altitude pulmonary edema is initially caused by an increased capillary pressure. Circulation 200 I; 1 03:2078-2083.

Malhotra R, Dhakal BP, Eisman AS, Pappagianopoulos PP, Dress A, Weiner RB, Baggish AL, Semigran MJ, Lewis GD. Pulmonary vascular distensibility predicts pulmonary hypertension severity, exercise capacity, and survival in heart failure. Circ Heart Fail 20 I 6;9:e0030I I.

Meister TA, Rimoldi SF, Soria R, von Arx R, Messerli FH, Sartori C, Scherrer $U$, Rexhaj E. Association of assisted reproductive technologies with arterial hypertension during adolescence. J Am Coll Cardiol 2018;72:1267-1274.

Naeije R, Vanderpool R, Dhakal BP, Saggar R, Saggar R, Vachiery JL, Lewis GD. Exercise-induced pulmonary hypertension: physiological basis and methodological concerns. Am J Respir Crit Care Med 2013; I 87:576-583.

Pavalescu A, Faoro V, Guenard H, de Bisschop C, Martinot JB, Mélot C, Naeije R. Pulmonary vascular reserve and exercise capacity at sea level and at high altitude. High Alt Med Biol 20I3; I4: 19-26.

Pereira N, Elias RT, Christos PJ, Petrini AC, Hancock K, Lekovich JP, Rosenwaks Z. Supraphysiologic estradiol is an independent predictor of low birth weight in full-term singletons born after fresh embryo transfer. Hum Reprod 2017;32:1410-1417.

Pinborg A. Short and long-term outcomes in children born after assisted reproductive technologies (ART). BJOG 2019;126: |45-| 48. 
Poon CS. Analysis of linear and mildly nonlinear relationships using pooled subject data. J Appl Physiol 1988;64:854-858.

Reeves JT, Linehan JH, Stenmark KR. Distensibility of the normal human lung circulation during exercise. Am J Physiol Lung Cell Mol Physiol 2005;288:L4I 9-L425.

Rexhaj E, Paoloni-Giacobino A, Rimoldi SF, Fuster DG, Anderegg M, Somm E, Bouillet E, Allemann Y, Sartori C, Scherrer U. Mice generated by in vitro fertilization exhibit vascular dysfunction and shortened life span. J Clin Invest 2013; I 23:5052-5060.

Roughton FJW, Forster RE. Relative importance of diffusion and chemical reaction rates in determining rate of exchange of gases in the human lung, with special reference to true diffusing capacity of pulmonary membrane and volume of blood in the lung capillaries. J Appl Physiol 1957; I I:290-302.

Rudski LG, Lai WW, Afilalo J, Hua L, Handschumacher MD, Chandrasekaran K, Solomon SD, Louie EK, Schiller NB. Guidelines for the echocardiographic assessment of the right heart in adults: a report from the American Society of Echocardiography endorsed by the European Association of Echocardiography, a registered branch of the European Society of Cardiology, and the Canadian Society of Echocardiography. J Am Soc Echocardiogr 2010;23:685-7I3.

Rudski LG, Gargani L, Armstrong WF, Lancellotti P, Lester SJ, Grünig E, D'Alto M, Åström Aneq M, Ferrara F, Saggar R et al. Stressing the cardiopulmonary vascular system: the role of echocardiography. J Am Soc Echocardiogr 20 18;3 I:527-550.

Scherrer U, Rimoldi SF, Rexhaj E, Stuber T, Duplain H, Garcin S, de Marchi SF, Nicod P, Germond M, Allemann Y et al. Systemic and pulmonary vascular dysfunction in children conceived by assisted reproductive technologies. Circulation 2012; 1 25:1890-1896.

Scherrer U, Rexhaj E, Allemann Y, Sartori C, Rimoldi S. Cardiovascular dysfunction in children conceived by assisted reproductive technologies. Eur Heart J 20 I 5;36: I583-1589.

Simaga B, Vicenzi M, Faoro V, Caravita S, Di Marco G, Forton K, Deboeck G, Lalande S, Naeije R. Pulmonary vascular function and exercise capacity in black sub-Saharan Africans. J Appl Physiol 2015; I | 9:502-507.
Simaga B, Forton K, Motoji Y, Naeije R, Faoro V. Lung diffusing capacity in sub-Saharan Africans versus European Caucasians. Resp Physiol Neurobiol 2017;241:23-27.

Soria R, Egger M, Scherrer U, Bender N, Rimoldi SF. Pulmonary artery pressure and arterial oxygen saturation in people living at high or low altitude: systematic review and meta-analysis. J Appl Physiol 2016; I2I:||5|-1|59.

Tello K, Axmann J, Ghofrani HA, Naeije R, Narcin N, Rieth A, Seeger W, Gall H, Richter MJ. Relevance of the TAPSE/PASP ratio in pulmonary arterial hypertension. Int J Cardiol 2018;266: 229-235.

Ten Harkel AD, Takken T, Van Osch-Gevers M, Helbing WA. Normal values for cardiopulmonary exercise testing in children. Eur J Cardiovasc Prev Rehabil 2011; 1 8:676-677.

Vonk Noordegraaf A, Westerhof BE, Westerhof N. The relationship between the right ventricle and its load in pulmonary hypertension. J Am Coll Cardiol 2017;69:236-243.

Vriz O, Argiento P, D'Alto M, Ferrara F, Vanderpool R, Naeije R, Bossone $\mathrm{E}$. Increased pulmonary vascular resistance in early stage systemic hypertension: a resting and exercise stress echocardiography study. Can J Cardiol 2015;3 1:537-543.

Wallenstein S, Zucker CL, Fleiss JL. Some statistical methods useful in circulation research. Circ Res 1980;47: I-9.

Wauters A, Vicenzi M, De Becker B, Riga JP, Esmaeilzadeh F, Faoro V, Vachiéry JL, van de Borne P, Argacha JF. At high cardiac output, diesel exhaust exposure increases pulmonary vascular resistance and decreases distensibility of pulmonary resistive vessels. Am J Physiol Heart Circ Physiol 2015;309:H2 I37-H2 144.

Whitelaw N, Bhattacharya S, Hoad G, Horgan GW, Hamilton M, Haggarty P. Epigenetic status in the offspring of spontaneous and assisted conception. Hum Reprod 2014;29:|452-1458.

Zavorsky GS, Hsia CC, Hughes JM, Borland CD, Guénard H, van der Lee I, Steenbruggen I, Naeije R, Cao J, Dinh-Xuan AT. Standardisation and application of the single-breath determination of nitric oxide uptake in the lung. Eur Respir J 2017;49: el 600962. 